\title{
PENERAPAN LITERASI DI DESA WISATA CIKOLELET MELALUI PERPUSTAKAAN KELILING DAN TAMAN BACAAN MASYARAKAT
}

\author{
Ida Nuraida ${ }^{1}$, Rd. Kania ${ }^{2}$, Fitri Dwirani ${ }^{3}$ \\ $1,2,3$ Universitas Banten Jaya, J1 Syech Nawawi Albantani Serang, Banten, Indonesia \\ Email: idanuraida@unbaja.ac.id ${ }^{1}$
}

\begin{abstract}
Literacy is the one of reading and writing skills capabilty. The Information of literacy as the competion have to give the information to society. The one Literacy implementation at the cikolelet vilages tourism have the purpose for critical thinking capabilty. The devlopment of Information and communication is veryhight, but did not always took society solution. The problem condition is the internet information linked gate and its make the user confuse. The libracy target is to give the socialization about education information and the library proggrame applied to the society are mobile library and library field. The other side, the litaracy implementation in Cikolelet vilage through mobile library and library field for society become the solution to looking for the information and become the inovation to icreasing the literacy society.
\end{abstract}

Keywords: Literacy, Mobile Library, Library Field

\begin{abstract}
ABSTRAK
Literasi adalah salah satu kemampuan keterampilan membaca dan menulis. Literasi informasi adalah suatu cara yang dilakukan agar mampu memberikan informasi kepada masyarakat dan membantu masyarakat dalam memecahkan permasalahannya. Salah satu penerapan literasi pada desa pariwisata Cikolelet bertujuan untuk meningkatkan kemampuan berpikir kritis masyarakatnya. Perkembangan teknologi informasi dan komunikasi yang tinggi tidak selalu mampu memberikan solusi bagi masyarakat. Permasalahannya adalah gerbang terkait informasi di internet membuat pengguna bingung sehingga perlu panduan berupa literasi dari perpustakaan dan lembaga lainnya. Sasaran perpustakaan adalah memberikan sosialisasi tentang informasi pendidikan dan program perpustakaan yang diterapkan kepada masyarakat yaitu perpustakaan keliling dan bidang perpustakaan. Di sisi lain, penerapan literasi di Desa Cikolelet melalui Perpustakaan Keliling dan Taman Baca Masyarakat menjadi solusi dalam mencari informasi dan menjadi inovasi untuk meningkatkan literasi masyarakat Desa Wisata Cikolelet.
\end{abstract}

Kata Kunci: Literasi, Perpustakaan Keliling, Bidang Perpustakaan

\section{PENDAHULUAN}

Desa Cikolelet Kecamatan Cinangka Kabupaten Serang terletak di sebelah barat ibu kota kabupaten jarak dari ibu kota kabupaten kurang lebih 45 KM, dari kantor Kecamatan Ke arah Utara sekitar $10 \mathrm{KM}$, Luas Desa Cikolelet Sekitar 954 Ha, sebelah timur berbatasan dengan Desa Cikedung, sebelah Barat Desa Baros Jaya, Utara Desa Mekarsari dan Selatan Berbatasan dengan Desa Kubang Baros. Desa Cikolelet terdiri dari 11 RW (Kampung), dengan jumlah Penduduk sebanyak 5106 jiwa dan jumlah KK 1.328 KK. 


\section{Demografi}

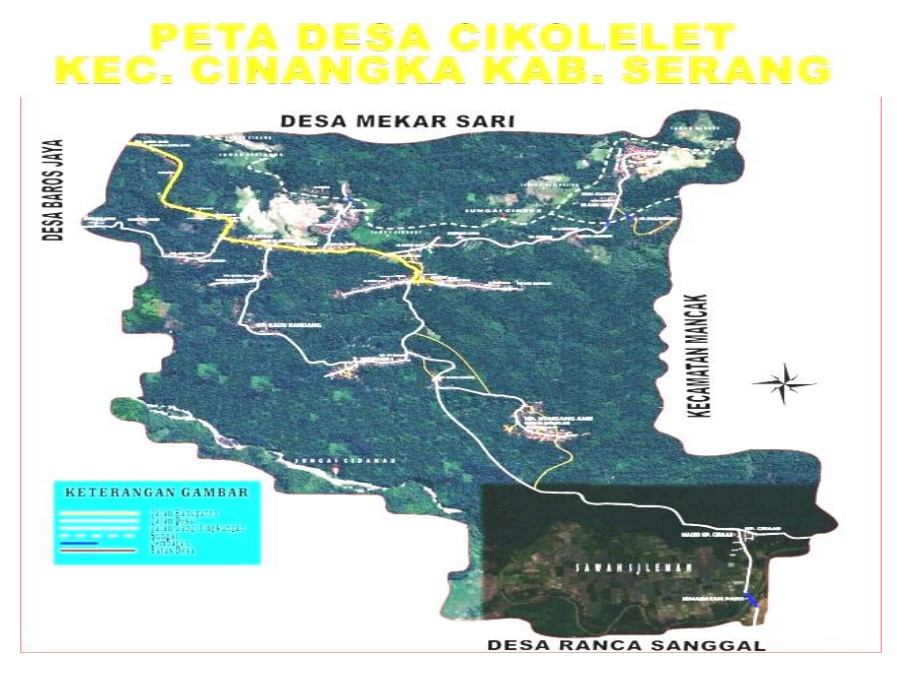

Gambar 1. Peta Desa Cikolelet

Desa adalah kesatuan masyakat hukum yang mempunyai batas-batas wilayah yang memiliki kewenangan untuk mengatur dan mengurus pemerintahan dan kepentingan masyarakat setempat berdasarkan hak asal usul, adat istiadat yang diakui dalam sistem pemerintahan nasional dan berada di wilayah kabupaten. Kebutuhan informasi untuk kondisi desa yang letak wilayah nya $45 \mathrm{KM}$ dari pusat kota masih kekurangan, dan masyarakat mengalami kebingungan dalam memilih informasi. Masyarakat dapat mengakases informasi dimanapun dengan pemanfaatan teknologi informasi, hal ini dapat menyebabkan masyarakat melek informasi akan tetapi di lain pihak memunculkan adanya kekuatiran akan pemanfaatan informasi yang tidak tepat(misalnya informasi hoax, pornografi, kekerasan, dan informasi tidak baik lainnya). Desa Cikolelet sebagai salah satu destinasi Desa Wisata, membutuhkan adanya media yang valid dan terpercaya dalam upaya memecahkan masalahnya, salah satunya dengan meningkatkan kegemaran membaca masyarakatnya, terutama pemuda dan anak-anak sebagai generasi penerus yang akan melanjutkan perkembangan desanya. Sebelum lebih jauh melangkah ke penggunaan informasi, sebaiknya mereka diarahkan untuk membaca buku dan melaksanakan penelusuran informasi sehat (internet sehat), seperti yang dilaksanakan oleh Taman Bacaan Masyarakat Azzam Desa Cikolelet dan yang dilaksanakan oleh Perpustakaan Keliling serta Mobil Pintar Dinas Perpustakaan dan Kearsipan Provinsi Banten.Pada umumnya pengguna media informasi yang ada adalah anak- anak sekolah dan pemuda desa yang masih terbatas. 


\section{Masyarakat Literasi}

Undang-Undang Nomor 43 tahun 2007 Tentang Perpustakaan Bab VII, JENIS-JENIS PERPUSTAKAAN, Bagian Kedua pasal 22 Ayat 5 menyatakan "Pemerintah, Pemerintah Provinsi dan/atau kabupaten/kota melaksanakan layanan perpustakaan keliling bagi daerah yang belum terjangkau oleh layanan perpustakaan menetap". Penjelasan pasal pasal 5 ayat 2 menyatakan "Masyarakat di daerah terpencil, terisolasi atau terbelakang akibat faktor geografis berhak mendapatkan layanan perpustakaan sesuai dengan kondisi setempat misalnya, perpustakaan keliling atau perpustakaan terapung”. Selain itu sesuai dengan Undang-Undang Nomor 43 tahun 2007 Tentang Perpustakaan, Bab XIII, PEMBUDAYAAN KEGEMARAN MEMBACA, pada pasal 48 sampai pasal 51, "Pemerintah mendorong program pembudayaan kegemaran membaca (literasi) terbangunnya masyarakat belajar pada semua lapisan usia, kelompok sosial, serta menjangkau seluruh lapisan masyarakat, dan dituntut berperan aktif serta mampu mengakomodir semua permasalahan yang ada sehingga program kegemaran membaca di kalangan masyarakat dapat dilaksanakan tepat sasaran". Masyarakat Indonesia pada gilirannya tidak lagi hanya menekankan pada minat baca (reading interest), tetapi akan menjadi kebiasaan membaca (reading habit), akan menjadi budaya baca (reading culture) dan akan terwujud masyarakat pembelajar sepanjang hayat (learning society). (Indonesia, 2009).

Hasil kajian dan evaluasi tentang kondisi minat dan kegemaran membaca masyarakat Indonesia, Perpustakaan Nasional RI tahun 2017, kondisi minat dan kegemaran membaca mengalami peningkatan 10 poin dari hasil kajian yang dilaksanakan tahun 2016 dari angka 26,5\% menjadi 36,48\%.(kemdikbud, n.d.) Hasil penelitian AKSI/INAP Kementrian Pendidikan dan Kebudayaan tahun 2016 menyatakan bahwa literasi baca tulis mengalami peningkatan. Keberhasilan ini tidak terlepas dari upaya yang telah dilakukan oleh pemerintah pusat yaitu Perpustakaan Nasional RI, Pemerintah Daerah (Dinas Perpustakaan dan Kearsipan Provinsi, Kabupaten/Kota, Kecamatan sampai tingkat Pemerintah Desa), para penggerak litarasi dan keterlibatan seluruh komponen masyarakat Indonesia sesuai dengan tupoksinya (OECD et al., 2017).

Undang-Undang N0.43 Pasal 49 menyatakan: "Pemerintah, pemerintah daerah, dan masyarakat mendorong timbulnya taman bacaan masyarakat dan rumah baca untuk menunjang pembudayaan kegemaran membaca."(Indonesia, 2009). Para ahli komunikasi dan kalangan masyarakat meyakini bahwa peradaban masa depan adalah masyarakat informasi (Information Society) yaitu peradaban di mana informasi sudah menjadi komoditas utama dan interaksi antar manusia berbasis teknoogi informasi dan komunikasi. Secara sederhana, untuk kebutuhan informasi 
maka diterapkankanlah budaya literasi, karena literasi dapat diartikan sebagai sebuah kemampuan membaca dan menulis. Kita mengenalnya dengan melek aksara atau keberaksaraan. Namun sekarang ini literasi memiliki arti luas, sehingga keberaksaraan bukan lagi bermakana tunggal, melainkan mengandung beragam arti (multi literacies).(Naibaho, 2011).

Ada bermacam-macam- keberaksaraan atau literasi, misalnya literasi komputer (computer literacy), literasi media (media literacy), literasi teknologi (teknologi literacy), literacy ekonomi (economy literacy), literasi informasi (information literacy), bahkan ada literasi moral (moral literacy). (Juditha, 2019) Jadi literasi dapat diartikan kebaruan inforamsi, berfikir kritis, peka terhadap lingkungan.Kepekaanatau literasi pada seseorang tentu tidak muncul begitu saja.

Pemerindah dan masyarakat membutuhkan proses panjang dan sarana yang kondusif untuk menciptakan generasi literat, proses ini dimulai dari kecil dan dari lingkungan keluarga, lalu didukung atau dikembangkan di sekolah. Budaya literasi juga sangat terkait dengan pola pembelajaran di sekolah dan ketersediaan bahan bacaan di perpustakaan. Menurut American Library Association (ALA), information literacy merupakan salah satu komponen penting yang harus di miliki oleh setiap warga dan berkontribusi dalam mencapai pemelajaran seumur hidup (Magpantay, 1996).

Kompetensi dalam information literacy bukan hanya sekedar pengetahuan di kelas formal, tetapi juga praktek langsung pada diri sendiri di lingkungan masyarakatnya, dan para ahli di bidang literasi informasi sepakat bahwa perpustakaan memiliki peran sangat penting dalam menciptakan masyarakat literasi. Perpustakaan memiliki kontribusi besar untuk membentuk masyarakat informasi yang berfikir kritis dan menjadi pembelajar seumur hidup. Pengelola perpustakaan melakukan terobosan baru yang salah satunya adalah implementasi perpustakaan keliing ke desadesa, salah satunya ke Desa Wisata Cikolelet dengan tujuan membantu masyarakat meningkatkan kemampuan literasinya dan berintegrasi dengan kurikulum merupakan sinergi dengan Taman Bacaan Masyarakat yang ada, merupakan salah satu solusi efektif.

\section{METODE}

Dalam penelitian ini digunakan pendekatan kualitatif (Somantri, 2005) untuk mengungkapkan permasalahan utama yang menjadi prioritas bagi masyarakat desa wisata Cikolelet Kecamatan Cinangka kabupaten serang provinsi banten adalah pemahaman masyarakat untuk mencari dan menggunakan inforamsi serta bagai mana mereka memaknai informasi yang salah satunya nanti membaatu untuk mensosialisasikan Desa Cikolelet sebagai destinasi wisata.Dalam hal ini, peneliti melakukan observasi partisipan, yaitu ikut serta dalam kegiatan yang dilakukan partisipan, sekaligus melakukan pengamatan terhadap pelaksanaan kegiatan. Selain itu, peneliti juga 
melakukan wawancara terhadap partisipan, yaitu masyarakat di desa Cikolelet dan Pembimbing kegiatan Kuliah Kerja Mahasiswa (KKM) di desa tersebut.

Langkah awal penelitian ini ialah mencari rincian permasalahan di desa Cikolelet dapat diuraikan sebagai berikut:

1. Rendahnya Budaya membaca masyarakat Desa Wisata Cikolelet

2. Masyarakat Desa Cikolelet belum semuanya faham bahwa untuk mencari informasi. Dan menciptakan kegiatan atau program yang fokus utama pengabdian kepada masyarakat yang diusulkan yaitu untuk meningkatka penerapan lietarsi di desa wisata cikolelet melaui perpustakaan keliling dan taman bacaan masyarakat.

\section{HASIL DAN PEMBAHASAN}

Solusi yang akan diterapkan untuk menangani permasalahan minimnya pengetahuan masyarakat desa cikolelet untuk mencari informasi dapat dipecahkan dengan penerapan literasi melaui perpustakaan keliling dan taman bacaan masyarakat. Perpustakaan Nasional Republik Indonesia sebagai sebuah lembaga pemerintah non departemen yang memiliki fungsi mengkaji dan menysun kebijakan yang bertujuan meningkatkan literasi masyarakat. (Kementerian Pendidikan dan Kebudayaan » Republik Indonesia, 2015). Beberapa pemikiran dasar yang dapat dijadikan Acuan adalah sebagai berikut:

Tabel 1. Contoh Kajian dan Kebijakan Perpustakaan Nasional Republik Indnesia

\begin{tabular}{|l|l|l|}
\hline No & \multicolumn{1}{|c|}{ Kondisi Objektif } & Tindakan yang dapat Dilakukan PNRI \\
\hline 1 & $\begin{array}{l}\text { Karakter Masyarakat (pengguna } \\
\text { Perpustakaan). } \\
\text { Masyarakat memiliki ciri dan karakter yang } \\
\text { khas dan beragam, anatara lain: lebih suka } \\
\text { berkumpul dalam komunitas tertentu. Ciri } \\
\text { inilah yang menciptakan banyaknya } \\
\text { perpustakaan komunitas da taman bacaan } \\
\text { dengan latar belakang khas. Umumnya } \\
\text { komunitas bercirikan kedaerahan. }\end{array}$ & $\begin{array}{l}\text { Berdayakan perpustakaan komunitas dan } \\
\text { daman bacaan dengan memberikan dukungan } \\
\text { pengelola perpustakaan komunitas dan taman } \\
\text { bacaan yang relevan dengan literasi informasi }\end{array}$ \\
\hline 2 & $\begin{array}{l}\text { Gap terhadap akses informasi. } \\
\text { Tiap kelompok masyarakat memiliki } \\
\text { keterbatasan akses yang berbeda. } \\
\text { Perkembangan teknologi informasi yang yang }\end{array}$ & $\begin{array}{l}\text { Berdayakan perpustakan umum daerah } \\
\text { dengan menyediakan koleksi terbaru dan } \\
\text { bermutu. Upayakan perpustakaan umum } \\
\text { daerah melakukan kegiatan-kegiatan yang }\end{array}$ \\
\hline
\end{tabular}




\begin{tabular}{|l|l|l|}
\hline & $\begin{array}{l}\text { tidak merata di setiap daerah membuat gap ini } \\
\text { semakin lebar. Di sisi lain, masyarakat yang } \\
\text { memiliki akses terhadap internet, cenderung } \\
\text { lebih mempercayai informasi yang ada di } \\
\text { internet tanpa berupaya mengevaluasi dengan } \\
\text { mencari sumber lain. }\end{array}$ & $\begin{array}{l}\text { menyentuh langsung pada literasi masyarakat. } \\
\text { Salah satu nya yaitu dengan mengadakan } \\
\text { program perpustakaan keliling ke desa. }\end{array}$ \\
\hline 3 & $\begin{array}{l}\text { Kurikulum belum mendukung. } \\
\text { Pola pembelajaran yang ada belum 'memaksa' } \\
\text { siswa dan mahasiswa untuk berfikir kritis. } \\
\text { Guru masih menjadi acuan utama. }\end{array}$ & $\begin{array}{l}\text { Kerjasama dengan DIKNAS untuk } \\
\text { mengembangkan kurikulum berbentuk } \\
\text { student centered' dengan model 'active } \\
\text { learning'. } \\
\text { Kerjasama dengan perguruan tinggi karena } \\
\text { perpustakaan perguruan tinggi memiliki } \\
\text { potensi besar untuk melakukan } \\
\text { pengembangan kurikulum lebih cepat. }\end{array}$ \\
\hline $\mathbf{4}$ & $\begin{array}{l}\text { Skema pengembangan belum fokus. } \\
\text { PNRI masih terlihat ingin mengembangkan } \\
\text { semua perpustakaan dalam waktu yang } \\
\text { bersamaan. }\end{array}$ & $\begin{array}{l}\text { Tentukan prioritas tiap tahun. Misalnya untuk } \\
\text { tahun 2007, jadikan perpustakaan umum } \\
\text { daerah di beberapa provinsi yang potensial } \\
\text { sebagai target kegiatan peningkatan literasi } \\
\text { masyarakat. }\end{array}$ \\
\hline
\end{tabular}

Tujuan dari program penerapan literasi di Desa Wisata Cikolelet melalui kegiatan perpustakan keliling adalah implementasi dari pemikiran dasar yang dijadikan acuan dari PNRI, karena lietrasi informasi merupakan kompetensi mutlak yang harus dimiliki setiap anggota masyarakat di era informasi. Jika masyarakat memliki tingkat literasi yang tinggi maka diharapkan masyarakat menjadi pembelajar sepanjang hayat dan mempu memecahkan permasalahan yang ada secara arif dan bijaksana, sehingga keberlangsungan sosial budaya yang ada dapat tetap lestari sesuai dengan nilai kearifan setempat (Indonesia, 2009). Tahapan pelaksanaan penerapan literasi di Desa Cikolelet melaui perpustakaan keliling dan taman bacaan masyarakat adalah sebagai berikut: 


\section{Penentuan Tujuan}

Penerapan Literasi untuk meningkatakan minat baca masyarakat di Desa Wisata Cikolelet melalui perpustkaan keliling dan Taman Bacaan Masyarakat

\section{Penetuan Materi Literasi}

Menentukan materi literasi yang diberikan kepada masyarakat dalam hal ini siswa. Dengan mendatangkan perpustakaan keliling ke desa wisata wisata cikolelet.

\section{Uji Coba Materi}

Melakukan uji coba analisis kelompok tertentu, dalam hal ini Siswa SDN Cipare Cikolelet.

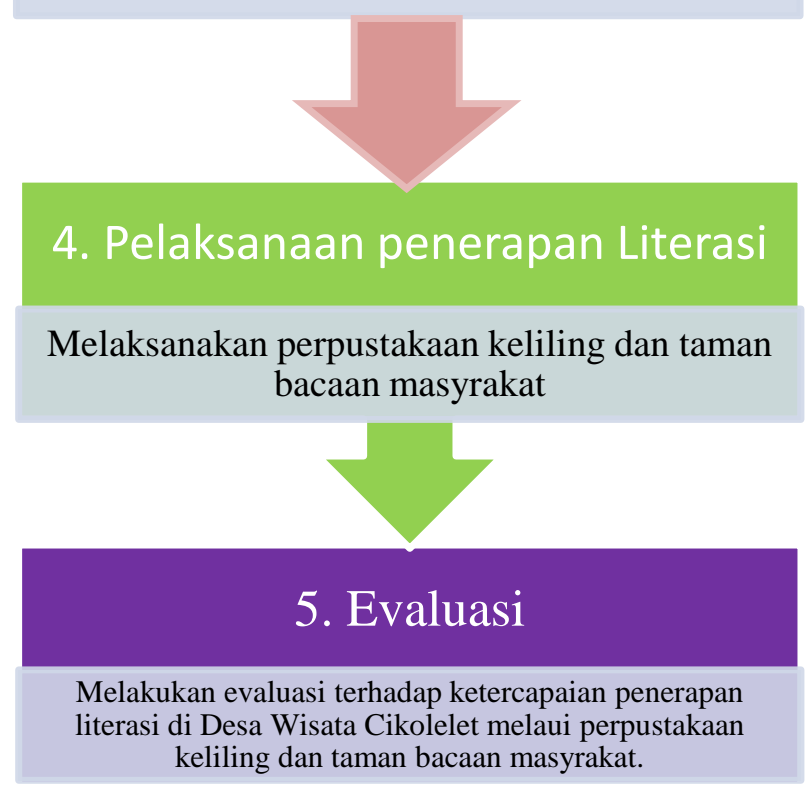

Diagram 1. Tahap Penerapan Literasi 

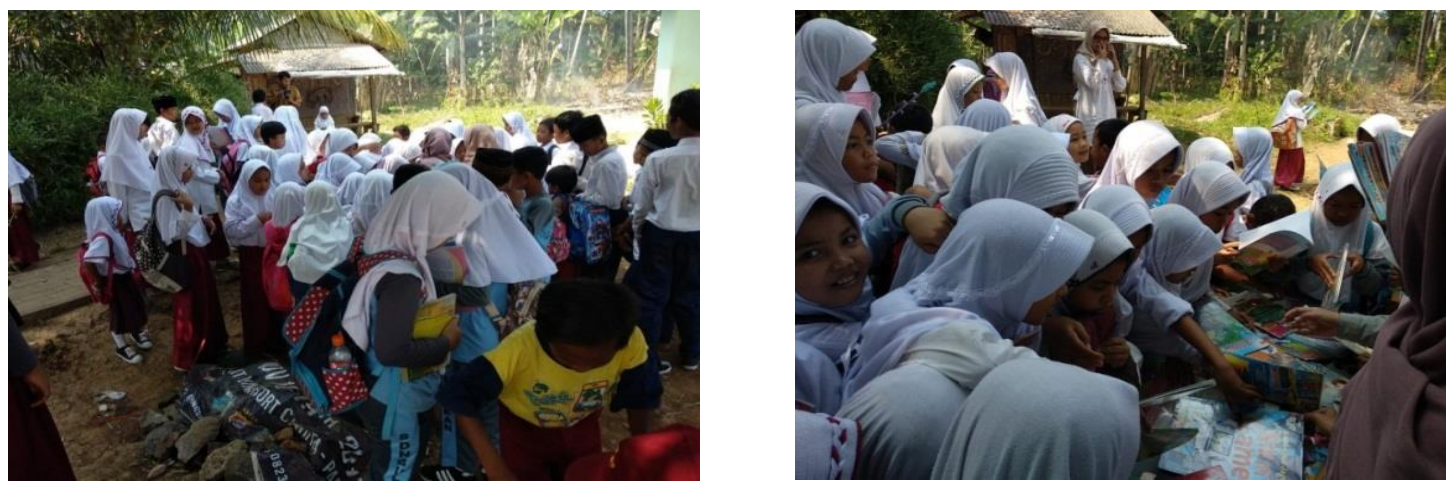

Gambar 2. Kegiatan Perpustakaan Keliling di Desa Wisata Cikolelet

\section{KESIMPULAN}

Berdasarkan kegiatan abdimas ini , dapat disimpulkan bahwa penerapan lietrasi di Desa Cikolelet melalui perpustakaan keliling dan taman bacaan masyarakat dapat di gunakan sebagai media (a) membentuk kesadaran sosial para partisipan (masyarakat), seperti yang terlihat dalam proses terlaksananya kegiatan perpustakaan keliling dan taman bacaan masyarakat, (b) membangkitkan tanggung jawab partisipan sebagai anggota masyarakat (civic Responsibility) dalam pengelolaan kegiatan perpustakaan keliling dan taman bacaan masyarakat, dengan cara bekerjasama dengan peneliti dan perpustakaan daerah untuk kesuksesan kegiatan tersebut.

\section{DAFTAR PUSTAKA}

Indonesia. (2009). UU No. 43 tahun 2007 tentang Perpustakaan.

Juditha, C. (2019). Literasi Informasi Melawan Hoaks Bidang Kesehatan di Komunitas Online. Jurnal ILMU KOMUNIKASI. https://doi.org/10.24002/jik.v16i1.1857

Kemdikbud. (n.d.). No Title. Retrieved from https://bbaceh.kemdikbud.go.id/2020/02/22 /sekilasgerakan-literasi-nasional-gln-tugas-masih-berat/

Kementerian Pendidikan dan Kebudayaan» Republik Indonesia. (2015). Target Kemendikbud Dalam Pengembangan Pendidikan dan Kebudayaan Tahun 2017.

Magpantay, A. (1996). American library association. Conference on Human Factors in Computing Systems - Proceedings. https://doi.org/10.1093/library/s1-9.1.124-b

Naibaho, K. (2011). Menciptakan Generasi Literat Melalui Perpustakaan. Retrieved from blog website: https://staff.blog.ui.ac.id/clara/page/5/ 
OECD, Kane, S. N., Mishra, A., Dutta, A. K., Sinha, S. B., Gupta, A., ... מحمد \& ع. (2017). Mencari Model Gerakan Literasi Masyarakat. Jurnal Ilmiah VISI P2TK PAUD NI. https://doi.org/10.1017/CBO9781107415324.004

Somantri, G. R. (2005). MEMAHAMI METODE KUALITATIF. Makara Human Behavior Studies in Asia. https://doi.org/10.7454/mssh.v9i2.122 